\title{
Bromocriptine approved as the first medication to target dopamine activity to improve glycemic control in patients with type 2 diabetes
}

This article was published in the following Dove Press journal:

Diabetes, Metabolic Syndrome and Obesity:Targets and Therapy

25 March 2010

Number of times this article has been viewed

\author{
Michael A Via' \\ Himani Chandra ${ }^{2}$ \\ Takako Araki' \\ Matthew $\vee$ Potenza $^{3}$ \\ Maria Skamagas ${ }^{4}$ \\ 'Division of Endocrinology and \\ Metabolism, Albert Einstein College \\ of Medicine, Beth Israel Medical \\ Center, New York, NY, USA; ${ }^{2}$ Division \\ of Endocrinology, Diabetes and \\ Bone Disease, Mount Sinai School \\ of Medicine, James J Peters VA Medical \\ Center, New York, NY, USA; ${ }^{3}$ Diabetes \\ and Endocrinology, West Nyack, \\ New York, NY, USA; ${ }^{4}$ Division of \\ Endocrinology, Diabetes and Bone \\ Disease, Mount Sinai School of \\ Medicine, New York, NY, USA
}

Correspondence: Michael Via 55 East 34th St, New York, NY 10016 , USA

$\mathrm{Fax}+\mathrm{I}(2 / 2)$ 252-6I79

Email mvia@chpnet.org
Abstract: Type 2 diabetes mellitus (T2DM) continues to rise in prevalence in the United States and worldwide. Despite advances in medical treatments for T2DM, many patients remain uncontrolled. By targeting centrally mediated pathways of glucose metabolism, bromocriptine represents a novel therapeutic option in T2DM. Several small clinical trials demonstrate improvements in insulin resistance and glycemic control. After the submission of data from four recent, large clinical trials, the US Food and Drug Administration has approved the use of bromocriptine in T2DM. We review the available data from these four trials and other published studies. Bromocriptine is a promising therapy for diabetes patients and demonstrates modest improvements in glycemic control.

Keywords: bromocriptine, dopamine agonists, diabetes, glycemic control

\section{Introduction}

The rise in prevalence of type 2 diabetes mellitus (T2DM) in recent decades parallels the rise in obesity in both the United States and worldwide. ${ }^{1}$ It is estimated that one-third of individuals born in the past decade will develop T2DM. ${ }^{1}$ The cost for treatment of the complications of T2DM may approach one half of medical expenditures. ${ }^{2}$ Recommended targeted goals can prevent complications and improve outcomes, but these are only met by $50 \%$ to $70 \%$ of individuals with T2DM despite current therapies. ${ }^{3}$

The treatment options for T2DM have also increased over the past 15 years. As we begin to understand some of the underlying pathophysiology in T2DM, our pharmacologic repertoire has expanded to target novel physiologic mechanisms. ${ }^{4}$ Still, many patients remain uncontrolled and the effectiveness of current therapies wanes over time. ${ }^{5,6}$ Newer classes of medical treatments for T2DM are promising for modification of disease progression, but they are expensive and there is little experience with use of these agents over the long term. ${ }^{4,7}$

Bromocriptine has been in clinical use for over 30 years. ${ }^{8}$ The utility of bromocriptine in diabetes patients has been proposed more recently, based on its activity in modulating central glucose and energy metabolism pathways. ${ }^{9}$ After several recent clinical trials, bromocriptine was approved by the United States Food and Drug Administration (FDA) for use in T2DM. ${ }^{10,11}$ The purpose of this paper is to review the current literature on the effects of bromocriptine (under the trade name Cycloset ${ }^{\mathbb{}}$; Veroscience, Tiverton, RI) in diabetes patients, including a proposed mechanism of action, a summary of the clinical trials in humans, and a discussion of safety and tolerability issues. Bromocriptine holds promise to be an effective treatment for T2DM. 


\section{Mechanism of action}

Bromocriptine is derived from an ergot alkaloid and functions as a postsynaptic dopamine receptor agonist and serotonin modulator. ${ }^{12}$ Clinically, bromocriptine is used to treat Parkinson's disease through activity at dopamine receptors in the nigrostriatal tract and to treat hyperprolactinemia and acromegaly via tuberoinfundibular pathways. ${ }^{12}$

Glucose and energy metabolism is tightly regulated by the central nervous system (CNS) mainly at centers in the medial basal hypothalamus. ${ }^{13}$ The CNS regulates hepatic glucose production through sympathetic pathways and integrates information on fuel availability through leptin, ghrelin, insulin, glucagon-like pepide-1 (GLP-1) and other hormonal signals. Diabetic and obese patients have impaired responses to these signal pathways and display elevations in hepatic glucose production, insulin resistance and impaired pancreatic $\beta$-cell function. ${ }^{7}$

The metabolic control pathways of the CNS are modulated, in part, by dopaminergic signaling. Agents that block dopamine activity, such as antipsychotic medications, are associated with impaired metabolism, weight gain, insulin resistance and dyslipidemia. ${ }^{14}$ To achieve the opposite effect, dopamine agonist therapy with bromocriptine has been proposed as a means of improving glucose and energy metabolism through activation of CNS dopaminergic pathways responsible for metabolic control. ${ }^{9}$

Multiple animal studies demonstrate metabolic improvements after the administration of bromocriptine including significant weight loss, decreased levels of blood glucose and triglycerides, decreased insulin resistance and increased glucose tolerance. ${ }^{15-19}$ Human studies show similar effects, though the results are not as profound. ${ }^{20-25}$ Dosages of bromocriptine in human trials have ranged from $2.5 \mathrm{mg}$ to $5 \mathrm{mg}$ per day. A rapid release form of bromocriptine (RR-bromocriptine; Cycloset $^{\mathbb{R}}$ ) is used in several of these trials, dosed at $4.8 \mathrm{mg}$ per day. ${ }^{11,20,21,23}$

The pharmacological activity of bromocriptine occurs mainly through activation of $\mathrm{D}_{2}$ receptors and inhibition of D1 receptors in the CNS. ${ }^{26}$ Bromocriptine also exhibits activity at serotonin receptors including inhibition of $5-\mathrm{HT}_{2 \mathrm{~A}}$ and partial agonism of $5-\mathrm{HT}_{2 \mathrm{~B}}$ receptors. ${ }^{27}$ The exact mechanism by which these pathways modulate glucose and energy metabolism remains to be elucidated.

\section{Published clinical trials}

In the current literature, there are 6 clinical trials using bromocriptine therapy for the treatment of T2DM and/or obesity. ${ }^{20-25}$ The results of these studies are summarized in Table 1 and reviewed below.

The first clinical study investigating the metabolic effects of bromocriptine was performed in $1992 .{ }^{24}$ In this observational trial, 33 non-diabetes obese subjects and 15 diabetes subjects were given bromocriptine $2.5 \mathrm{mg}$ daily and followed weekly for 4 to 8 weeks. In the diabetes group, fasting glucose decreased from $283 \mathrm{mg} / \mathrm{dL}$ to $184 \mathrm{mg} / \mathrm{dL}$ in subjects on insulin regimens, while fasting glucose levels decreased from 231 to 166 for those who were on oral hypoglycemic regimens. The mean weight loss was $1.1 \mathrm{~kg}$ in the diabetes group.

A second observational study followed 13 obese nondiabetes female subjects with hyperinsulinemia after 8 weeks of open-label therapy with RR-bromocriptine, $4.8 \mathrm{mg}$ daily. ${ }^{23}$ At baseline and again at the study endpoint, hourly plasma glucose, insulin, triglyceride and free fatty acid concentrations were measured over a 24-hour period in each subject. A slight, but significant $(P<0.05)$ decrease was noted in

Table I Summary of published clinical trials

\begin{tabular}{|c|c|c|c|c|c|c|c|}
\hline \multirow[t]{2}{*}{ Study } & \multirow[t]{2}{*}{ Subjects } & \multirow[t]{2}{*}{$\mathbf{n}$} & \multirow{2}{*}{$\begin{array}{l}\text { Bromocriptine } \\
\text { Dosage }\end{array}$} & \multirow{2}{*}{$\frac{\text { Duration }}{\text { (Weeks) }}$} & \multicolumn{3}{|l|}{ Results - change in } \\
\hline & & & & & Fasting BG (mg/dL) & $\mathrm{HbA}_{\mathrm{lc}}(\%)$ & Weight \\
\hline \multicolumn{8}{|c|}{ Observational trials } \\
\hline \multirow[t]{3}{*}{ Meier et $\mathrm{a}^{24}$} & OB & 33 & $1.25 \mathrm{mg}$ daily & 6 & NA & NA & $-2.3 \mathrm{~kg}$ \\
\hline & DM2 & 15 & $2.5 \mathrm{mg}$ daily & $4-8$ & -99 insulin group & NA & $-1.1 \mathrm{~kg}$ \\
\hline & & & & & -65 oral agent group & & \\
\hline Kamath et $\mathrm{a}^{23}$ & OB & 13 & $4.8 \mathrm{mg}$ daily & 8 & no change & NA & NA \\
\hline \multicolumn{8}{|l|}{ Randomized trials } \\
\hline Cincotta et $\mathrm{a}^{20}$ & $\mathrm{OB}$ & 17 & 1.6 to $2.4 \mathrm{mg}$ daily & 18 & no change & NA & $-6.3 \mathrm{~kg}$ \\
\hline Pijl et $a^{21}$ & DM2 & 22 & $4.8 \mathrm{mg}$ daily & 16 & -28 & -0.6 & no change \\
\hline Aminorroaya et $\mathrm{al}^{22}$ & DM2 & 40 & $2.5 \mathrm{mg}$ daily & 12 & -27 & -0.4 & no change \\
\hline Wasada et $\mathrm{al}^{25}$ & DM2 & 13 & $2.5 \mathrm{mg} 2 \times$ daily & 30 & no change & NA & no change \\
\hline
\end{tabular}

Abbreviations: DM2, type 2 diabetics; OB, obese non-diabetics; $\mathrm{HbA}_{1 \mathrm{c}}$, glycosylated hemoglobin; BG, blood glucose; NA, data not available. 
plasma glucose, triglycerides and free fatty acids. The degree of change in plasma glucose was less than $18 \mathrm{mg} / \mathrm{dL}$, and only observed in a 3-hour period after lunch. There was no significant change in the 24-hour insulin levels.

Cincotta et al, conducted a double blind, placebocontrolled trial of RR-bromocriptine in 17 obese subjects with impaired glucose tolerance, of which 5 had diabetes..$^{20}$ Daily dosages ranged from 1.6 to $2.4 \mathrm{mg}$ in the eight patients who received RR-bromocriptine. After 18 weeks of follow up, the RR-bromocriptine group demonstrated significant weight loss of $6.3 \pm 1.5 \mathrm{~kg}(P<0.01)$ and had a $46 \%$ decrease in area under the serum glucose curve during an oral glucose tolerance test $(P<0.02)$ compared to baseline. No changes were noted in the placebo group.

Two double-blind, placebo-controlled trials that investigate the use of RR-bromocriptine in obese patients with T2DM show significant metabolic improvements..$^{21,22}$ The first trial enrolled 22 subjects that were followed for 16 weeks. ${ }^{21}$ At the study endpoint, fasting plasma glucose decreased by $17 \mathrm{mg} / \mathrm{dL}$, mean change in plasma glucose after oral glucose tolerance testing decreased by $22 \mathrm{mg} / \mathrm{dL}$ and glycosylated hemoglobin $\left(\mathrm{HbA}_{1 \mathrm{c}}\right)$ was reduced by $0.6 \%$ compared to placebo. The second trial enrolled 40 subjects that were followed for 3 months. ${ }^{22}$ Fasting plasma glucose decreased by $27 \mathrm{mg} / \mathrm{dL}$ and $\mathrm{HbA}_{1 \mathrm{c}}$ remained unchanged, compared to an $\mathrm{HbA}_{1 \mathrm{c}}$ increase by $1.1 \%$ in the placebo group.

A third double-blind, placebo-controlled trial was conducted using twice daily dosing of bromocriptine in 13 obese diabetes patients. ${ }^{25}$ The study drug in this trial was not a rapid release form of bromocriptine. After 6 to 8 months, there were no significant changes in percent body fat, visceral fat or in the homeostasis model assessment of insulin resistance following a standardized meal. $\mathrm{HbA}_{1 \mathrm{c}}$ was not measured.

The results from these 6 trials in humans show moderate improvements in glycemic control and in metabolic markers using RR-bromocriptine to treat patients with T2DM. These studies are relatively brief and enroll a small number of patients. Most of the studies required run in periods with dose increases of RR-bromocriptine on a weekly basis, which further shortens the length of optimal RR-bromocriptine exposure. Studies with longer term follow up may show additional benefits.

The formulation of bromocriptine is also important. In these clinical studies, 5 out of 6 studies that showed clinical benefits used RR-bromocriptine..$^{20-24}$ The one study that used an ordinary form of bromocriptine showed no benefit. ${ }^{25}$ Since "fine tuning" seems important for effects on hypothalamic circadian rhythm, RR-bromocriptine may be required to meet the concept and hypothesis of improved glucose and energy metabolism through CNS mediation.

\section{Clinical trials of RR-bromocriptine for FDA approval}

The results of several relatively large clinical trials have prompted the FDA to approve RR-bromocriptine for use in T2DM. ${ }^{11,28,29}$ These studies have yet to be formally published. We summarize their results from available sources.

A single clinical trial using RR-bromocriptine to treat T2DM was presented at the 2008 annual meeting of the American Diabetes Association (ADA). ${ }^{10}$ In this study, 3070 diabetes subjects were randomized to receive RR-bromocriptine or placebo $(2: 1)$ in addition to their usual diabetes therapy. The authors report a $42 \%$ relative reduction in cardiovascular events with use of RR-bromocriptine ( $P=0.036 ; 1.5 \%$ RR-bromocriptine vs $2.96 \%$ placebo event rate) at 52-week follow up. It should be noted, however, that there were significant baseline differences in the two groups including increased rates of cardiac revascularization procedures and increased rates of stroke in the placebo group before the trial started. Whether these baseline differences contributed to the overall study outcome requires further investigation.

A second presentation was given at the 2009 ADA meeting that analyzed markers of glycemic control in this same trial, focusing only on the subgroup of participants who were failing thiazolidinedione therapy $(\mathrm{n}=52 \mathrm{RR}$-bromocriptine group; $\mathrm{n}=68$ placebo group). After 1 year, levels of $\mathrm{HbA}_{1 \mathrm{c}}$ were lower in the RR-bromocriptine group compared to placebo. For subjects with baseline $\mathrm{HbA}_{1 \mathrm{c}} \geq 8.5 \%$ or $\geq 7.5 \%$, treatment with RR-bromocriptine decreased $\mathrm{HbA}_{1 \mathrm{c}}$ by $1.21 \%$ $(P<0.05)$ and $0.57 \%(P<0.05)$ compared to placebo, respectively. ${ }^{29}$

The results of this 52-week trial have yet to be formally published. The same group has performed three other 24-week trials using RR-bromocriptine to treat T2DM. Results from these three trials are also unpublished, but are summarized online. ${ }^{28}$

The first 24-week trial used RR-bromocriptine monotherapy or placebo monotherapy in 159 patients with uncontrolled T2DM. After 24 weeks, $\mathrm{HbA}_{1 \mathrm{c}}$ decreased by $0.1 \%$ in the RR-bromocriptine group (baseline $\mathrm{HbA}_{1 \mathrm{c}}=9.0 \%$ ) versus a $0.3 \%$ increase in the placebo group $(P<0.05){ }^{28}$

The second 24-week trial, "Study L", involved 249 T2DM patients inadequately controlled on sulfonylurea therapy. 
Enrolled subjects were given RR-bromocriptine or placebo in addition to their current medication. After 24 weeks, $\mathrm{HbA}_{1 \mathrm{c}}$ decreased by $0.4 \%$ in the RR-bromocriptine group (baseline $\mathrm{HbA}_{1 \mathrm{c}}=9.0 \%$ ) versus a $0.3 \%$ increase in the placebo group $(P<0.001){ }^{28}$

The third 24-week trial, "Study K", enrolled 245 patients with T2DM that were also inadequately treated with sulfonylurea therapy. Enrolled subjects were given RR-bromocriptine or placebo in addition to their current medication. After 24 weeks, $\mathrm{HbA}_{1 \mathrm{c}}$ decreased by $0.1 \%$ in the RR-bromocriptine group (baseline $\mathrm{HbA}_{1 \mathrm{c}}=9.3 \%$ ) versus a $0.4 \%$ increase in the placebo group $(P<0.001) .{ }^{28}$

The results of these four studies served as the basis for the FDA approval of RR-bromocriptine for the treatment of T2DM. While the apparent results of these trials are statistically significant, the small improvements seen in diabetes control may only have a modest clinical impact. The observed decrease in cardiovascular outcomes seen with RR-bromocriptine in the 52 -week trial may be the result of poor randomization. As of January, 2010, none of these four trials have been published in peer reviewed journals. Further scrutiny of these trials is warranted and we anxiously await their publication.

\section{Pharmacokinetics}

The peak activity of RR-bromocriptine $\left(\right.$ Cycloset $^{\mathbb{R}}$ ) occurs 1 to 3 hours following oral ingestion and its plasma half-life is approximately 15 hours. ${ }^{12}$ The vast majority (90\%-96\%) of circulating bromocriptine is protein-bound. ${ }^{12}$ Due to this relatively short half-life, bromocriptine is often administered in divided doses for the treatment of Parkinson's disease or hyperprolactinemia, usually 2 to 3 times daily. ${ }^{26}$ In the human trials of diabetes patients, RR-bromocriptine is given as a once-daily morning dose. ${ }^{20-25}$ Daily cycling of dopamine agonism may be important for improvements in glycemic control. ${ }^{21}$

Bromocriptine is metabolized in the liver by the CYP3A4 cytochrome system. Medications that inhibit this pathway, such as macrolide antibiotics, protease inhibitors or anti-fungal therapies will raise circulating levels of bromocriptine. ${ }^{12}$ Inducers of CYP3A4 activity, such as phenytoin or St. John's wort, decrease bromocriptine levels and can lead to ineffectiveness of therapy. ${ }^{12}$

\section{Safety of bromocriptine}

The accumulated data from 3 decades of clinical trials and post-marketing analysis in patients with Parkinson's disease, hyperprolactinemia, and acromegaly treated with bromocriptine demonstrate relative safe use. Serious events are uncommon and usually occur at high cumulative doses. The most common side effects of bromocriptine are benign: nausea, vomiting, dizziness, hypotension, headache, and fatigue. ${ }^{8,30,31}$ More serious side effects are rare and include psychosis, fibrosis (retroperitoneal, pleural, cardiac valve), and cardiovascular events (myocardial infarction, stroke). ${ }^{31}$ The post-marketing reports of fibrosis events involve higher doses of bromocriptine. ${ }^{32}$ With regards to the adverse cardiac effects, bromocriptine demonstrates substantially lower risk than cabergoline, another commonly prescribed dopaminergic agent. ${ }^{33,34}$

RR-bromocriptine use in T2DM differs from typical bromocriptine therapy in the aforementioned conditions. Thus, it is possible that the side effect profile used T2DM may differ. However, the dose approved for treatment of T2DM is 2- to 3-fold lower than usual doses in hyperprolactinemia and 10- to 20-fold lower than treatment for Parkinson's disease. These relatively low doses for treatment of T2DM may reduce the risk of adverse effects. On the other hand, it is possible that the RR-bromocriptine may increase the risk and/or severity of side effects as compared to typical bromocriptine or modified release bromocriptine (Parlodel ${ }^{\circledR}$; Novartis) preparations.

Side effect and safety data of RR-bromocriptine in T2DM are available from two 6-month trials and a 1-year safety trial. ${ }^{10,20,23}$ At this time, available post-marketing data are limited.

Overall, RR-bromocriptine demonstrates good safety and tolerability. Gastrointestinal side effects are among the most common reported adverse events, which include nausea in $26 \%$ to $33 \%$ and vomiting in $5 \%$ to $8 \%$ of subjects. Dizziness is another common side effect, and is reported in $12 \%$ to $15 \%$ of subjects. Discontinuation of RR-bromocriptine due to adverse reactions was mainly attributable to nausea and less frequently to dizziness. Thirteen percent of RR-bromocriptine users withdrew from a monotherapy trial and add-on to sulfonylurea trial, compared to placebo withdrawal of $3 \%(P<0.00001)$ and $5 \%(P=\mathrm{NS}){ }^{9}$ Orthostatic hypotension and syncope are less common. Asthenia or weakness occurred in $15 \%$, headache in $11 \%$ to $17 \%$, fatigue in $14 \%$, and constipation in $6 \%$ to $11 \%$ of subjects. ${ }^{9,10}$ These side effects tend to present on initiation or titration of RR-bromocriptine, and appear to be minimized by gradual weekly titration.

To fulfill FDA requirements and demonstrate drug safety, Scranton et al, conducted an industry sponsored trial that examined the overall safety, cardiovascular safety, and efficacy of RR-bromocriptine for treatment of T2DM. 
The study included 3070 patients with a 1-year follow up period. ${ }^{10,11}$ Adverse events were reported in $8.5 \%$ in the RR-bromocriptine group of $9.6 \%$ of placebo group ( $P=\mathrm{NS})$. Rates of hypoglycemia were similar in RR-bromocriptine users compared to placebo. Reported hypoglycemia occurred in $2.5 \%$ of those on RR-bromocriptine monotherapy, $8.6 \%$ in combination with sulfonylurea, and $6.9 \%$ as add on therapy. Severe hypoglycemia (blood glucose $<50 \mathrm{mg} / \mathrm{dL}$ and neurologic symptoms requiring assistance with treatment) occurred in $0.5 \%$ of RR-bromocriptine users compared to $1 \%$ of placebo group. ${ }^{11}$

To date, there have been no serious adverse events (fibrosis or psychosis) reported in bromocriptine or RRbromocriptine use in T2DM. These effects are much less common with bromocriptine therapy compared with the use of other ergot-derived agents, however there may be potential for low dose RR-bromocriptine to cause fibrosis. ${ }^{33-35}$ Longterm studies are needed to assess the cumulative dosage safety of RR-bromocryptine.

\section{Patient adherence}

Despite well-established guidelines for glycemic control, many diabetes patients do not achieve targeted goals. ${ }^{3}$ Adherence to prescribed medicine, dietary and lifestyle regimens are all crucial factors in T2DM management. Diabetes patients often cite medication cost, forgetfulness to take medications, comorbid depression and concern for weight gain, hypoglycemia or other adverse effects as reasons for nonadherence to prescribed medication regimens. ${ }^{36}$

With regard to these factors, RR-bromocriptine has advantages over other new and existing diabetes therapies. For patients who do not always remember to take their medications, the once-daily dosing schedule of bromocriptine fits easily into most daily routines, which may aid in medication adherence. However, adherence may be reduced by the 6-tablet ( $0.8 \mathrm{mg}$ each) optimal dose that is approved for treatment of T2DM.

Bromocriptine has several other clinical properties that are favorable to diabetes patients. Therapy with bromocriptine is associated with a small degree of weight loss and is not associated with increased rates of hypoglycemia or weight gain. ${ }^{20-25}$ Bromocriptine also causes mild decreases in blood pressure by 3 to $7 \mathrm{mmHg}$ systolic,,${ }^{8,30,37}$ which may be helpful as the majority of diabetes patients are hypertensive. ${ }^{38}$ Some authors argue that dopamine agonists such as bromocriptine have beneficial effects on depression, ${ }^{39}$ which also has a high prevalence in the diabetes population and is associated with poor glycemic control. ${ }^{36}$
The mild adverse effects discussed above may limit its use in certain patients. Approximately $50 \%$ of treated patients experience one of the common, benign adverse effects, which usually do not lead to discontinuation of therapy. ${ }^{8,30}$

The trials for bromocriptine use in T2DM show a near $100 \%$ adherence rate confirmed by suppression of prolactin levels. ${ }^{20-25}$ However, some patients were unable to achieve dosage targets. In trials investigating the treatment of Parkinson's disease and hyperprolactinemia, patients also demonstrate a high degree of adherence (96\%-98\%) despite multiple daily dosages of bromocriptine. ${ }^{8,37}$ In general, bromocriptine is well tolerated and most individuals are adherent to therapy. An advantage of bromocriptine over other diabetes medications is that adherence can be assessed directly by measuring serum prolactin.

\section{Conclusion}

Although in clinical use for other indications for over 30 years, bromocriptine represents a novel agent that targets a unique pathway in the management of T2DM. While the exact mechanism remains to be elucidated, the known activity of bromocriptine through dopamine agonism may modulate CNS regulatory pathways of glucose and energy metabolism. A number of small clinical trials have shown modest improvements in glycemic control using RR-bromocriptine. Larger, unpublished trials seem to confirm mild benefits using RR-bromocriptine in T2DM patients.

Presently, it is not clear how RR-bromocriptine would fit in the current recommended strategy for medical treatment of diabetes. ${ }^{3}$ We speculate that bromocriptine may have optimal effects if used early in the course of the disease, possibly in combination with other potential disease-modifying therapies such as metformin, thiazolidinediones, or GLP-1 agonists. However, since a subgroup analysis showed benefit in patients who were failing therapy with thiazolidinediones, ${ }^{29}$ RR-bromocriptine may have utility later in the course of T2DM as well. We await publication of several large trials to confirm the potential benefits of RR-bromocriptine for diabetes patients. ${ }^{10,11}$

\section{Disclosures}

The authors disclose no conflicts of interest.

\section{References}

1. Johnson WD, Kroon JJ, Greenway FL, Bouchard C, Ryan D, Katzmarzyk PT. Prevalence of risk factors for metabolic syndrome in adolescents: National Health and Nutrition Examination Survey (NHANES), 2001-2006. Arch Pediatr Adolesc Med. 2009;163:371-377.

2. Ryan JG. Cost and policy implications from the increasing prevalence of obesity and diabetes mellitus. Gend Med. 2009;6 Suppl 1:86-108. 
3. ADA. 2008 Standards of medical care in diabetes -2008 . Diabetes Care. 2008;31 Suppl 1:S12-S54.

4. Nathan DM. Finding new treatments for diabetes-how many, how fast ... how good? $N$ Engl J Med. 2007;356:437-440.

5. Kahn SE, Haffner SM, Heise MA, et al. Glycemic durability of rosiglitazone, metformin, or glyburide monotherapy. $N$ Engl J Med. 2006;355:2427-2443.

6. Turner RC, Cull CA, Frighi V, Holman RR. Glycemic control with diet, sulfonylurea, metformin, or insulin in patients with type 2 diabetes mellitus: progressive requirement for multiple therapies (UKPDS 49). UK Prospective Diabetes Study (UKPDS) Group. JAMA. 1999;281:2005-2012.

7. Defronzo RA. Banting Lecture. From the triumvirate to the ominous octet: a new paradigm for the treatment of type 2 diabetes mellitus. Diabetes. 2009;58:773-795.

8. Colao A, Di Sarno A, Guerra E, De Leo M, Mentone A, Lombardi G. Drug insight: cabergoline and bromocriptine in the treatment of hyperprolactinemia in men and women. Nat Clin Pract Endocrinol Metab. 2006;2:200-210.

9. Cincotta AH, Meier AH, Cincotta Jr M. Bromocriptine improves glycaemic control and serum lipid profile in obese Type 2 diabetic subjects: a new approach in the treatment of diabetes. Expert Opin Investig Drugs. 1999;8:1683-1707.

10. Scranton R, Cincotta, A, Gaziano, JM. The effect of timed Cycloset (a quick-release formulation of bromocriptine mesylate) on cardiovascular events in patients with type 2 diabetes [abstract]. Diabetes. 2008;57:A95.

11. Scranton RE, Gaziano JM, Rutty D, Ezrokhi M, Cincotta A. A randomized, double-blind, placebo-controlled trial to assess safety and tolerability during treatment of type 2 diabetes with usual diabetes therapy and either Cycloset or placebo. BMC Endocr Disord. 2007;7:3.

12. Kvernmo T, Hartter S, Burger E. A review of the receptor-binding and pharmacokinetic properties of dopamine agonists. Clin Ther. 2006;28:1065-1078.

13. Sandoval D, Cota D, Seeley RJ. The integrative role of CNS fuelsensing mechanisms in energy balance and glucose regulation. Аnпu Rev Physiol. 2008;70:513-535.

14. Tschoner A, Engl J, Laimer M, et al. Metabolic side effects of antipsychotic medication. Int J Clin Pract. 2007;61:1356-1370.

15. Cincotta AH, MacEachern TA, Meier AH. Bromocriptine redirects metabolism and prevents seasonal onset of obese hyperinsulinemic state in Syrian hamsters. Am J Physiol. 1993;264:E285-E293.

16. Cincotta AH, Meier AH. Reductions of body fat stores and total plasma cholesterol and triglyceride concentrations in several species by bromocriptine treatment. Life Sci. 1989;45:2247-2254.

17. Cincotta AH, Meier AH, Southern LL. Bromocriptine alters hormone rhythms and lipid metabolism in swine. Ann Nutr Metab. 1989;33: 305-314.

18. Southern LL, Cincotta AH, Meier AH, Bidner TD, Watkins KL. Bromocriptine-induced reduction of body fat in pigs. J Anim Sci. 1990;68:931-936.

19. Cincotta AH, Schiller BC, Meier AH. Bromocriptine inhibits the seasonally occurring obesity, hyperinsulinemia, insulin resistance, and impaired glucose tolerance in the Syrian hamster, Mesocricetus auratus. Metabolism. 1991;40:639-644.
20. Cincotta AH, Meier AH. Bromocriptine (Ergoset) reduces body weight and improves glucose tolerance in obese subjects. Diabetes Care. 1996;19:667-670.

21. Pijl H, Ohashi S, Matsuda M, et al. Bromocriptine: a novel approach to the treatment of type 2 diabetes. Diabetes Care. 2000;23:1154-1161.

22. Aminorroaya A, Janghorbani M, Ramezani M, Haghighi S, Amini M. Does bromocriptine improve glycemic control of obese type-2 diabetics? Horm Res. 2004;62:55-59.

23. Kamath V, Jones CN, Yip JC, et al. Effects of a quick-release form of bromocriptine (Ergoset) on fasting and postprandial plasma glucose, insulin, lipid, and lipoprotein concentrations in obese nondiabetic hyperinsulinemic women. Diabetes Care. 1997;20:1697-1701.

24. Meier AH, Cincotta AH, Lovell WC. Timed bromocriptine administration reduces body fat stores in obese subjects and hyperglycemia in type II diabetics. Experientia. 1992;48:248-253.

25. Wasada T, Kawahara R, Iwamoto Y. Lack of evidence for bromocriptine effect on glucose tolerance, insulin resistance, and body fat stores in obese type 2 diabetic patients. Diabetes Care. 2000;23:1039-1040.

26. Tan EK, Jankovic J. Choosing dopamine agonists in Parkinson's disease. Clin Neuropharmacol. 2001;24:247-253.

27. Jahnichen S, Horowski R, Pertz HH. Agonism at 5-HT2B receptors is not a class effect of the ergolines. Eur J Pharmacol. 2005;513:225-228.

28. http://www.centerwatch.com/drug-information/fda-approvals/ drug-details.aspx?DrugID=1020. Accessed Dec 10, 2009.

29. Scranton RE EM, Gaziano JM, Cincotta A. Cycloset (bromocriptine mesylate accelerated absorbing) therapy improves glycemic control in type 2 diabetes (T2D) subjects failing thiazolidinedione (TZD) therapy [abstract]. American Diabetes Association 69th Annual Meeting; June 8, 2009:Abstract 481-P.

30. van Hilten JJ, Ramaker CC, Stowe R, Ives NJ. Bromocriptine versus levodopa in early Parkinson's disease. Cochrane Database Syst Rev. 2007; CD002258.

31. Weil C. The safety of bromocriptine in long-term use: a review of the literature. Curr Med Res Opin. 1986;10:25-51.

32. Wiggins J, Skinner C. Bromocriptine induced pleuropulmonary fibrosis. Thorax. 1986;41:328-330.

33. Horvath J, Fross RD, Kleiner-Fisman G, et al. Severe multivalvular heart disease: a new complication of the ergot derivative dopamine agonists. Mov Disord. 2004;19:656-662.

34. Zanettini R, Antonini A, Gatto G, Gentile R, Tesei S, Pezzoli G. Valvular heart disease and the use of dopamine agonists for Parkinson's disease. N Engl J Med. 2007;356:39-46.

35. Serratrice J, Disdier P, Habib G, Viallet F, Weiller PJ. Fibrotic valvular heart disease subsequent to bromocriptine treatment. Cardiol Rev. 2002;10:334-336.

36. Daly JM, Hartz AJ, Xu Y, et al. An assessment of attitudes, behaviors, and outcomes of patients with type 2 diabetes. J Am Board Fam Med. 2009:22:280-290

37. Katzenschlager R, Head J, Schrag A, Ben-Shlomo Y, Evans A, Lees AJ. Fourteen-year final report of the randomized PDRG-UK trial comparing three initial treatments in PD. Neurology. 2008;71:474-480.

38. Sahay BK, Sahay RK. Hypertension in diabetes. J Indian Med Assoc. 2003;101:12, 14-15, 44.

39. Clausius N, Born C, Grunze H. The relevance of dopamine agonists in the treatment of depression. Neuropsychiatr. 2009;23:15-25.

Diabetes, Metabolic Syndrome and Obesity: Targets and Therapy

\section{Publish your work in this journal}

Diabetes, Metabolic Syndrome and Obesity: Targets and Therapy is an international, peer-reviewed open-access journal committed to the rapid publication of the latest laboratory and clinical findings in the fields of diabetes, metabolic syndrome and obesity research. Original research, review, case reports, hypothesis formation, expert opinion and commentaries are all considered for publication. The manuscript management system is completely online and includes a very quick and fair peer-review system, which is all easy to use. Visit http://www.dovepress.com/testimonials.php to read real quotes from published authors. 